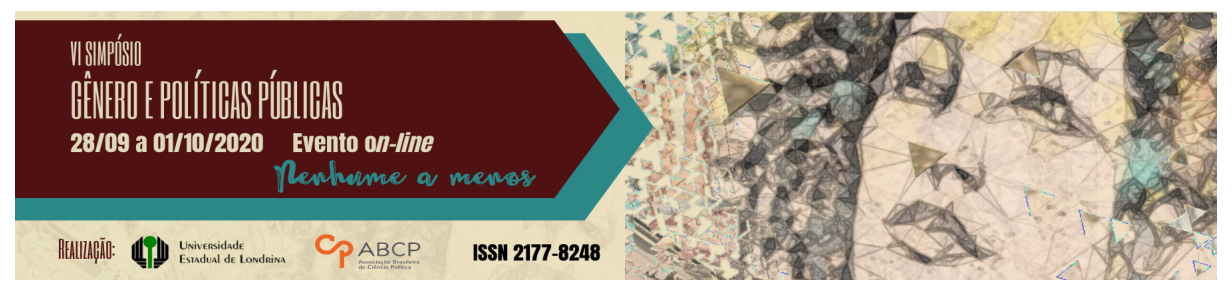

\title{
A violência doméstica contra a idosa e a possibilidade de aplicação da teoria do diálogo das fontes
}

\author{
Patrícia Tuma Martins Bertolin"; Artenira da Silva e Silva²; Werdeson Mário \\ Cavalcante Olimpio ${ }^{3}$
}

\section{Resumo}

A feminização da velhice vai além do simples aumento demográfico de mulheres idosas em relação aos homens, abarcando questões como a violência doméstica. Paralelamente, o Judiciário ainda debate acerca do conflito negativo de competência entre a Vara da Mulher e a Vara do Idoso para o processamento e julgamento de casos de violência doméstica contra a idosa. $O$ presente estudo objetiva analisar a possibilidade de aplicação da tese do diálogo das fontes aos casos de violência doméstica contra a mulher idosa no Brasil. Para isso, realizou-se uma pesquisa bibliográfica e o estudo de caso de duas decisões proferidas pela $2^{\text {a }}$ Vara da Comarca de Rosário/MA presidida pelo magistrado José Augusto Sá Costa Leite. Com isso, observou-se que a tese dos diálogos das fontes pode ser aplicada nessa situação, ante a necessidade de uma relação de complementaridade entre as normas e não uma relação de exclusão.

\footnotetext{
1 Professora permanente do Programa de Pós-Graduação em Direito Político e Econômico da Universidade Presbiteriana Mackenzie (UPM). Doutora em Direito pela Universidade de São Paulo, com Pós-Doutorado na Superintendência de Educação e Pesquisa da Fundação Carlos Chagas. Líder do grupo de pesquisa (CNPq) "Mulher, Sociedade e Direitos Humanos". E-mail: ptmb@uol.com.br.

2 Professora permanente do Programa de Pós-Graduação em Direito e Instituições do Sistema de Justiça da Universidade federal do Maranhão. Pós-doutora em Direitos Humanos na Universidade Federal do Pará. Possui graduação em Psicologia pela Pontifícia Universidade Católica de São Paulo (1990), mestrado em Saúde e Ambiente pela Universidade Federal do Maranhão (2000), doutorado em Saúde Coletiva pela Universidade Federal da Bahia (2005) e pós-doutorado em Psicologia e Educação pela Universidade do Porto, Portugal (2014).). E-mail: artenirassilva@hotmail.com.

${ }^{3}$ Mestrando do Curso de Pós-Graduação em Direito e Instituições do Sistema de Justiça da Universidade Federal do Maranhão. Especialista em Direito e Prática Previdenciária pela Universidade Estácio de Sá. Possui graduação em Direito pela Universidade Federal do Maranhão (2016). Bolsista da FAPEMA. Email: werdesonolimpio@hotmail.com.
}

GT 21 - Violência de gênero 
Palavras-chave: violência doméstica; Idosa; Tese do diálogo das fontes.

\section{Introdução}

A velhice é a fase final do ciclo da vida humana. Não é à toa que a vulnerabilidade é característica das pessoas que pertencem a tal grupo, haja vista que às fragilidades do tempo somam-se as discriminações sociais frente a própria velhice. O fato é que o processo de envelhecimento populacional é uma realidade mundial e, atrelado ao mesmo, percebe-se uma discriminação social e um despreparo do Estado quanto esse contingente exponencial de idosos.

Ligada ao envelhecimento populacional, destaca-se a feminização da velhice, que vai além do simples crescimento demográfico das mulheres idosas frente aos homens idosos, posto que se levantam questões sociais, como os alarmantes índices de violência doméstica contra essas mulheres na terceira idade.

Paralelo a esse cenário, verifica-se que os juízes e promotores continuam a suscitar o conflito negativo de competência entre a Vara da Mulher e a Vara do Idoso, mesmo havendo um forte entendimento pela competência da Vara da Mulher. Contudo, seria esse o ponto central de discussão frente a um suposto conflito aparente entre a Lei Maria da Penha e o Estatuto do Idoso?

Em razão de tal contexto, o presente artigo objetiva analisar a possibilidade de aplicação da tese do diálogo das fontes aos casos de violência doméstica contra a mulher idosa no Brasil, a partir do estudo de caso de duas decisões proferidas pela $2^{\text {a }}$ Vara da Comarca de Rosário no Maranhão presidida pelo magistrado José Augusto Sá Costa Leite.

Inicialmente, buscou-se analisar o fenômeno da feminização da velhice no Brasil, a fim de compreender as suas implicações para além de um simples crescimento demográfico da população de mulheres acima de 60 anos. A seguir, buscou-se verificar o cenário da violência 
doméstica contra a idosa no citado país e o debate relativo aos conflitos negativos de competência entre a Vara da Mulher e a Vara do Idoso.

Por conseguinte, analisou-se a tese do diálogo das fontes e suas implicações no que se refere aos conflitos aparentes das normas frente a complexidade dos ordenamentos jurídicos pós-modernos. Por fim, efetuou-se uma análise da possibilidade de aplicação da tese do diálogo das fontes às situações de violência doméstica contra a mulher idosa em face do estudo de caso de duas decisões da $2^{\mathrm{a}}$ Vara da Comarca de Rosário.

\section{A feminização da velhice no Brasil}

O ciclo natural do ser humano ocorre basicamente em três fases: a infância, a fase adulta e a velhice. Nesse sentido, o envelhecimento é um processo inevitável e atinente à própria natureza humana. Há de chegar o dia em que as rugas, os passos lentos, os lapsos de memória, entre outras características atinentes à idade avançada, farão parte do cotidiano de todos.

$\mathrm{O}$ art. $2^{\circ}$ da Lei $\mathrm{n}^{\circ}$ 8.842/94 (Política Nacional do Idoso) 4 e, logo a seguir, o art. $1^{\circ}$ do Estatuto do Idoso (Lei $\left.n^{\circ} 10.741 / 03\right)^{5}$ asseveram que qualquer pessoa com idade igual ou superior a 60 anos é considerada idosa no Brasil. Outros termos são utilizados para definir essas pessoas: velhos, indivíduos na terceira idade. No entanto, há que se ressaltar a carga pejorativa inerente ao termo "velhos", visto que dá a ideia de inutilidade, diferentemente do que ocorre com o termo "idoso" o qual designa um respeito a condição de idade avançada, bem como o termo "terceira idade" que é originário da superação de uma visão negativa da velhice a uma fase ativa e de valorização da pessoa idosa (BILYNSKYJI, 2016, p. 55-56).

\footnotetext{
4 "Art. $2^{\circ}$ Considera-se idoso, para os efeitos desta lei, a pessoa maior de sessenta anos de idade."

5 "Art. 1o É instituído o Estatuto do Idoso, destinado a regular os direitos assegurados às pessoas com idade igual ou superior a 60 (sessenta) anos."
} 
O certo é que a população brasileira vem passando por um processo gradual de envelhecimento. Em 2017, a população de idosos no Brasil era de 30,2 milhões, número que vem crescendo, podendo chegar ao quantitativo correspondente a $25,5 \%$ do total da população brasileira em 2060 (PARADELLA, 2018). Há alguns fatores que explicam essa transformação demográfica nacional os quais emergiram a partir da década de 70: a conversão de uma sociedade majoritariamente rural (tradicional, numerosa e com altos índices de mortalidade na infância) para uma sociedade urbana com menos filhos e com novos arranjos familiares (MIRANDA; MENDES; SILVA, 2018, p. 508).

Dentro desse cenário, verifica-se que o processo de feminização da velhice, isto é, o quantitativo de mulheres com idade de 60 anos ou mais supera o número de homens idosos. Segundo dados do IBGE, a população idosa cresceu 18\% entre 2012 e 2017 e que as mulheres representam 56\% desta população. Nesse ínterim, as estimativas são de que as mulheres vivem, em média, quase sete anos a mais que os homens.

Uma análise precipitada implicaria em avaliar tal estimativa de forma positiva, posto que as mulheres possuem uma expectativa de vida maior que os homens. Entretanto, segundo Nicodemo e Godoi (2010, p. 41)

As desigualdades por sexo promovidas pelas condições estruturais e socioeconômicas em muitas situações alteram inclusive as condições de saúde, renda e a dinâmica familiar e têm forte impacto nas demandas por políticas públicas e prestação de serviços de proteção social. Viver mais não é sinônimo de viver melhor. As mulheres acumulam, no decorrer da vida, desvantagens (violência, discriminação, salários inferiores aos dos homens, dupla jornada, etc.) e têm maior probabilidade de serem mais pobres do que os homens e dependendo assim de mais recursos externos. 
Nesse sentido, esse fenômeno engloba muitos outros fatores, devendo ir além de uma simples questão demográfica, abarcando os reflexos da divisão sexual do trabalho e o debate dentro das esferas pública e privada (LINS; ANDRADE, 2018, p. 441).

Nota-se, ainda, a imprescindibilidade da discussão acerca da ideia de gênero e patriarcado. Nos ensinamentos de Saffioti (2004, p. 4445), a ideia de gênero está atrelada a construção social do masculino e feminino, enquanto o patriarcado corresponde ao regime de dominação do homem sobre a mulher. Com isso, é evidente a ligação entre a questão do gênero e a divisão do trabalho, em que se vislumbra a ultrapassada visão da mulher como a responsável pelos afazeres domésticos e educação dos filhos, enquanto seria papel do homem sustentar materialmente a família. Essa visão ainda se encontra presente em muitos ambientes familiares, sendo de suma importância, quando da análise da figura da mulher idosa.

Velha, nos moldes da modernidade ocidental, é a mulher que perde a sua condição social de reprodutora, somada às desigualdades provenientes da idade avançada em razão das tradições culturais, influências sociais e estilos de vida (EGYDIO, 2017, p.41). Com isso, percebe-se que a discriminação sofrida pela mulher idosa interliga-se a um sexismo que compreende que as mulheres são úteis até o momento em que deixam de ser atraentes e úteis aos homens, tornando-se mulheres moldadas para temerem a velhice, negando veementemente o processo natural de envelhecimento (SALGADO, 2002, p. 11-12).

Ademais, atrelado ao contexto até aqui exposto, deve-se ressaltar o fato de que a imensa parte das idosas nunca chegou a trabalhar ou a contribuir com a Previdência Social, possuindo uma baixa escolaridade e configurando uma situação de dependência a qual demanda políticas públicas e demais atuações por parte do Estado (SOARES, 2012, p. 183). Salgado (2002, p. 13-14), nessa linha, aduz que

Após uma vida sem receber rendimentos ou salários adequados, não é acidental que a mulher, na velhice, seja mais pobre que o homem. Apesar de muitas 
mulheres de idade avançada precisarem suprir certas necessidades básicas, enfrentam mais a pobreza do que quando eram jovens. Entre as razões que se pode assinalar para este fato, cita-se: não se dá compensação, reconhecimento ou direito à aposentadoria a mulheres cujo trabalho tenha sido primordialmente doméstico; devido à discriminação sexual, as mulheres ganham menos e, por esta razão, as aposentadorias são mais baixas; caso decidam voltar a trabalhar, não são admitidas por falta de experiência recente ou pela idade; muitas não têm direito à pensão de seus maridos por serem muito jovens.

Desse modo, evidenciou-se que o fenômeno de feminização da velhice, mais do que uma simples questão demográfica em que o número de idosas supera o de idosos, caracteriza-se pela discussão tanto no âmbito público, quanto privado de questões como o gênero e patriarcado, políticas públicas, garantias de direitos e atuação estatal acerca desse grupo vulnerável.

\section{A violência doméstica contra a idosa no Brasil}

Conforme disposto no item anterior, a maior longevidade das mulheres não é tida, como se poderia imaginar inicialmente, como algo positivo. Essas idosas possuem uma vida inteira de dificuldades inerentes ao seu gênero e sujeitas, em sua grande parcela, a ideia do patriarcado, sofrendo discriminações, dupla jornada de trabalho e, principalmente, a violência doméstica e ou familiar. Nesse sentido, sofrem duplamente, isto é, pelas marcas da terceira idade e pelo seu gênero.

Dados obtidos da Secretaria dos Direitos Humanos por meio do Disque 100 demonstraram que houve mais de 33 mil denúncias de abusos contra idosos no Brasil em 2017 (ONU BRASIL, 2019). Já no ano de 2018, foi registrado um aumento de 13\% de denúncias no Disque 100 em relação ao ano anterior. Foram recebidas mais de 37 mil denúncias 
nos mais diversos tipos de violência: negligência (38\%), violência psicológica $(26 \%)$, violência física $(12 \%)$ e violência patrimonial (aproximadamente 20\%) (G1, 2019).

Além disso, merece destaque o fato de que, apenas nos primeiros seis meses de 2018, foram recebidas 5.206 denúncias de violência contra mulheres idosas na Central de Atendimento à Mulher. Ademais, nesse mesmo período, o serviço do Disque 100 registrou 34.928 denúncias contra idosos no país, ressaltando que $63,25 \%$ desse total referiam-se a denúncias de violência contra mulheres idosas (GOVERNO DO BRASIL; 2018).

Vale ressaltar, que os números citados não são plenamente capazes de evidenciar o real quantitativo de violências contra a mulher idosa que ocorrem no Brasil. Por ser um tipo de violência que na maioria dos casos, ocorre dentro do âmbito familiar, a mulher idosa teme pelas consequências jurídicas sobre os seus agressores, em grande parte, filhos e netos com os quais a vítima possui um forte vínculo afetivo e, por vezes, dependem financeiramente ou necessitam dos "cuidados" dos seus descendentes. Nesse sentido, observa-se que

Cabe considerar que, como as mulheres jovens e adultas, as idosas encontram-se emocionalmente vinculadas a seus agressores e assim também evitam levar a juízo a violência sofrida, pois estas decorrem das relações afetivas com o agressor, como filhos e netos. $\mathrm{O}$ medo, culpa e vergonha em relação às violências sofridas, além de acharem que podem enfraquecer os laços familiares fazem com que elas tenham ainda o receio de abandono e desprezo de seus entes caso levem a juízo essa situação de violência que elas perpassam. (VELOSO, 2016, p. 133)

Com isso, a mulher brasileira idosa surge como figura inserida em todo esse cenário, comumente eclipsada nos discursos e na agenda política, muito embora sofra as mais variadas mazelas em razão de sua dupla vulnerabilidade (por gênero e por faixa etária), sendo vítima frequente de maus-tratos, abusos, agressões físicas, verbais e 
patrimoniais durante toda uma vida, gerando graves consequências no momento em que atinge a terceira idade.

A garantia ao idoso do direito à segurança e a uma vida sem nenhum tipo de violência, independentemente do sexo, gênero ou identidade de gênero está presente no art. $9^{\circ}$ da Convenção Interamericana Sobre a Proteção dos Direitos Humanos dos Idosos ${ }^{6}$. No mesmo sentido, é o que recorda a Convenção Belém do Pará no seu preâmbulo7.

Por sua vez, a Constituição Brasileira de 1988 tem diversas normas voltadas à mulher idosa, garantindo-lhe a isonomia (art. $5^{\circ}$, caput $^{8}$ ) e culminando ao Estado, à família e à sociedade em geral o dever da garantia e defesa da dignidade e bem-estar da idosa (art. 2309). Alinhado à Constituição, o Estatuto do Idoso predispõe o direito ao respeito a pessoa idosa, englobando a garantia da integridade física, psíquica e moral (art. 10, $\S 2^{\circ}$ ), bem como outros mecanismos que abarcam uma atuação positiva estatal na garantia de direitos dessa população idosa. Além disso, haja vista que o fator etário não possui o condão de excluir o gênero da mulher idosa, observa-se a aplicação da Lei Maria da Penha, que estabelece:

Art. $2^{\circ}$ Toda mulher, independentemente de classe, raça, etnia, orientação sexual, renda, cultura, nível educacional, idade e religião, goza dos direitos fundamentais inerentes à pessoa humana, sendo-lhe

\footnotetext{
6 “[...] O idoso tem direito à segurança e a uma vida sem nenhum tipo de violência, a receber um tratamento digno e a ser respeitado e valorizado, independentemente da raça, cor, sexo, idioma, cultura, religião, opinião política ou de outra índole, origem social, nacional, étnica, indígena e identidade cultural, posição socioeconômica, deficiência, orientação sexual, gênero, identidade de gênero, sua contribuição econômica ou qualquer outra condição. [...]" (grifo nosso)

7 "[...] a violência contra a mulher permeia todos os setores da sociedade, independentemente de classe, raça ou grupo étnico, renda, cultura, nível educacional, idade ou religião, e afeta negativamente suas próprias bases;" (grifo nosso).

8 "Art. $5^{\circ}$ Todos são iguais perante a lei, sem distinção de qualquer natureza, garantindose aos brasileiros e aos estrangeiros residentes no País a inviolabilidade do direito à vida, à liberdade, à igualdade, à segurança e à propriedade, nos termos seguintes:"

9 “Art. 230. A família, a sociedade e o Estado têm o dever de amparar as pessoas idosas, assegurando sua participação na comunidade, defendendo sua dignidade e bem-estar e garantindo-lhes o direito à vida."
} 
asseguradas as oportunidades e facilidades para viver sem violência, preservar sua saúde física e mental e seu aperfeiçoamento moral, intelectual e social (grifo nosso).

Nota-se com o exposto que, embora haja um arcabouço jurídico de proteção da mulher idosa em situação de violência doméstica, os números desse tipo de violência a esse grupo vulnerável não vêm diminuindo nos últimos anos. E o Estado tem uma grande parcela de responsabilidade em relação a esse cenário, inclusive no que concerne às instituições do sistema de justiça.

Em muitas situações, as autoridades públicas não estão tecnicamente preparadas para o enfrentamento desse tipo de violência. O despreparo pode ocorrer desde o atendimento policial que, por vezes, desestimula essa mulher idosa a denunciar seu agressor; ao delegado que entende que não seja caso de o inquérito policial tramitar em uma Delegacia Especializada de Violência contra a Mulher; ao magistrado que não concede as medidas protetivas de urgência necessárias ou não aplica as normativas jurídicas nacionais e internacionais que melhor protegem a mulher idosa, declinando da competência da Vara Especializada da Violência Doméstica contra a Mulher para julgar os crimes em comento.

O debate acerca do conflito negativo de competência entre a Vara da Mulher e Vara do Idoso é uma das questões que interferem na melhor atuação do Judiciário. Embora, o aparato normativo seja expresso quanto a possibilidade de aplicação da Lei Maria da Penha em casos de violência doméstica contra a mulher, ainda são suscitados diversos conflitos entre as varas citadas, sendo prolatados acórdãos delimitando a competência da Vara do Idoso em virtude de uma dissociação entre fator etário e o gênero ${ }^{10}$. Em sentido contrário a esse

\footnotetext{
10 São vários os julgados com esse entendimento, tais como: TJPE, Conflito de Jurisdição 324449-5, relator Marco Antônio Cabral Maggi, data da publicação 01/07/2014; TJPE, Conflito de Jurisdição 329478-6, relator Fausto de Castro Campos, data da publicação 06/05/2014; Recurso em Sentido Estrito No 70051925097, Sétima Câmara Criminal, Tribunal de Justiça do RS, Relator: Carlos Alberto Etcheverry, Julgado em 18/12/2012 etc.
} 
último posicionamento, Araújo (2018, p. 231-232) defende a competência da Vara da Mulher, uma vez que Lei Maria da Penha por ser posterior ao Estatuto do Idoso é regra especial, uma vez que é expressa no que condiz a defesa de violência doméstica contra a mulher independentemente da idade, devendo ser aplicada no caso concreto.

O certo é que o entendimento da citada autora é o que ocorre na grande maioria dos Tribunais. A título de exemplo, Veloso (2016, p. 9498), em sua dissertação, realizou uma análise dos conflitos negativos de competência entre a Vara Especializada no Combate a Violência contra a Mulher e da $8^{\text {a }}$ Vara Criminal ${ }^{11}$ nas Câmaras Criminais do Tribunal de Justiça do Estado do Maranhão (TJ/MA) no período de 2011 a 2015, encontrando 9 acórdãos que, em quase toda sua totalidade, alinham-se para a sedimentação do entendimento pela competência da Vara Especializada no Combate a Violência contra a Mulher para o processamento e julgamento de casos atinentes a violência doméstica contra a mulher idosa. Não obstante, a citada autora concluiu que, embora o TJ/MA possua tal entendimento, os conflitos continuam a ser suscitados, posto que ainda há divergência entre magistrados e promotores quanto a efetiva competência, sendo, assim, ainda um tema longe de ser pacificado (VELOSO, 2016, p. 132-133).

Nesse ínterim, embora a competência tenha sua importância no que concerne a organização do Judiciário e melhor atuação da prestação jurisdicional, compreende-se que o debate acerca da conflito negativo de competência entre a Vara da mulher e do Idoso é inócuo ante ao verdadeiro foco da questão, a garantia dos direitos fundamentais da mulher idosa frente a atuação do Judiciário. Com isso, passa-se a análise da teoria do diálogo das fontes como uma possível forma de superação do embate supracitado.

\footnotetext{
11 No Maranhão, a Vara Especial do Idoso ainda não se encontra efetivada. Dessa forma, o art. $8^{\circ}$ da Lei Complementar $n^{\circ} 140 / 2011$ determinou que a competência para o processamento e julgamento dos crimes previstos no Estatuto do Idoso serão da $8^{\mathrm{a}}$ vara Criminal da Comarca de São Luís do Maranhão a qual também é competente para o processamento e julgamento dos crimes contra a ordem econômica, tributária e das relações de consumo.
} 


\section{A tese do diálogo das fontes}

Com o avançar dos anos, as relações humanas tornam-se mais complexas e, consequentemente, o Direito não acompanha na mesma velocidade a tutela dessas novas relações, ocasionando os chamados vazios ou lacunas jurídicas as quais costumam ser integradas pelo julgador através da analogia, os costumes ou pelos chamados princípios gerais do direito (art. $4^{\circ}$ da Lei de Introdução às Normas do Direito Brasileiro - LINDB'2).

As lacunas do direito não são as únicas problemáticas jurídicas as quais emergem nesse cenário. Ante a tamanha complexidade, inúmeras normas ou microssistemas jurídicos foram promulgadas nos ordenamentos jurídicos atuais, inclusive o brasileiro, gerando possíveis antinomias, isto é, quando "uma norma determina uma certa conduta como devida e outra norma determina também como devida uma outra conduta, inconciliável com aquela" (KELSEN, 2006, p. 228-229).

Para a solução de tais antinomias, usualmente usavam-se os critérios: $1^{\circ}$ ) hierárquico, quando a norma superior dá o fundamento de validade da inferior, derrogando-a (KELSEN, 2006, p. 217); $2^{\circ}$ ) cronológico (norma nova prevalece sobre a antiga - art. $2^{\circ} \S 1^{\circ}$ da LINDB $^{13}$ ) e da especialidade (lei específica sobrepõe-se a lei geral - art. $2^{\circ}, \S 2^{\circ}$ da LINDB $\left.{ }^{14}\right)$.

No entanto, ante a própria complexidade dos ordenamentos jurídicos esses métodos de solução de antinomias não são eficientes, fazendo com que nascesse a tese do diálogo das fontes por Erik Jayme na Alemanha, tendo sido importada ao Brasil pela professora Claudia

\footnotetext{
12 “Art. 4o Quando a lei for omissa, o juiz decidirá o caso de acordo com a analogia, os costumes e os princípios gerais de direito."

13 "§ 1o A lei posterior revoga a anterior quando expressamente o declare, quando seja com ela incompatível ou quando regule inteiramente a matéria de que tratava a lei anterior."

14 "§ 20 A lei nova, que estabeleça disposições gerais ou especiais a par das já existentes, não revoga nem modifica a lei anterior."
} 
Lima Marques, delimitando que as normas jurídicas, mesmo que de ramos jurídicos distintos, não se excluem, mas se complementam, trazendo uma visão unitária do Direito, como é o caso da aplicação do Código de Defesa do Consumidor (CDC) e do Código Civil (CC) (TARTUCE, 2018, p. 77-78).

Cláudia Lima Marques (2013, p.128), defendendo a coexistência e aplicação simultânea do CDC e do Código Civil, apresenta três espécies de diálogo: $\mathbf{1}^{\circ}$ ) diálogo sistemático de coerência , em que há a aplicação concomitante das duas leis, em que uma delas pode servir de base conceitual a outra, sendo característico que uma lei é geral e a outra especial em que pode ocorrer a complementação do conteúdo de uma em relação a outra; $2^{\circ}$ ) diálogo sistemático de complementaridade e subsidiariedade, ou seja, há aplicação complementar ou subsidiária, podendo ocorrer de uma depender da aplicação da outra ao caso concreto; e, por fim, $3^{\circ}$ ) diálogo de coordenação e adaptação sistemática, traz influências recíprocas, ocorrendo uma possível redefinição do campo de aplicação de uma lei bem como a sua influência, seja da geral para a especial ou da especial para geral, ou seja, alguns conceitos estruturais de uma lei sofrem influências da outra.

Orientando da citada autora, em sua tese de doutorado, Valério de Oliveira Mazzuoli (2008, p. 221-222) defendeu a aplicação da teoria do diálogo das fontes aos possíveis conflitos entre as normas de direito internacional e de direito interno no Brasil, posto que, quando se fala em efetivação dos direitos humanos, a utilização fechada de "uma norma ou outra" fere a proteção que ambas as normas tem a possibilidade de ensejar, sendo a teoria do diálogo das fontes possibilita a coexistência, harmonia e convivência. Mazzuoli (2008, p. 228) assevera, em uma de suas conclusões, que

É salutar ao sistema jurídico a transigência das normas em lugar da intransigência e da exclusão de uma norma por outra. Se há transigência é porque houve diálogo e, se houve diálogo, é porque a solução do conflito proveio do próprio sistema jurídico, em demonstração de que ele (o sistema jurídico) almeja 
sempre a melhor solução para um conflito de normas ou até mesmo de interesses. O juiz, neste caso, terá por missão 'coordenar' tais fontes jurídicas e 'escutar' o que elas dizem. Ouvido o diálogo das fontes estará o magistrado habilitado a aplicar a 'solução' (ou a 'conclusão') do respectivo diálogo, atribuindo a cada ser humano protegido o melhor (mais benéfico) direito no caso concreto.

Observa-se, dessa maneira, que a tese do diálogo das fontes surgiu como uma necessidade de solução de conflitos de normas frente à complexidade das novas problemáticas sociais e das normas integrantes dos ordenamentos jurídicos, posto que os critérios de solução tradicionais (hierárquico, cronológico e de especialidade) não são suficientes. Diferente desses últimos, a tese do diálogo das fontes possibilita a coexistência e harmonia entre as duas normas inicialmente conflitantes, inclusive quando se tratam de normas de direito internacional e de direito interno, devendo o magistrado assegurar uma aplicação justa e equilibrada dos dispositivos, sem a exclusão ou invalidação de quaisquer das normas em conflito.

\section{Violência doméstica contra a idosa à luz da tese do diálogo das fontes}

Conforme exposto anteriormente, a população brasileira passa por um processo de feminização da velhice, que implica em questões problemáticas, tanto no âmbito privado, quanto público. $\mathrm{O}$ cenário brasileiro é de violência às mulheres, sendo ainda mais severo quando essas últimas chegam a terceira idade, uma vez que há uma somatória de discriminações e responsabilidades a elas impostas durante toda a vida, pelo Patriarcado ${ }^{15}$. Ademais, esse quadro de violência é preocupante, ante a omissão de um Estado que não prepara devidamente as suas autoridade públicas acerca de uma problemática tão latente, bem como de um grupo vulnerável que pouco conhece seus direitos e pouco espaço possui na agenda política e, mesmo sofrendo os

15 Patriarcado, na acepção do termo adotada pelas feministas a partir da década de 1970, descreve um sistema social marcado pela dominação masculina (DELPHY, 2009). 
mais diversos tipos de violência, teme pelas consequências jurídicas que podem ser impostas a seus agressores, em sua maioria filhos e netos com os quais possui forte vínculo afetivo.

Embora haja um arcabouço jurídico nacional e internacional de proteção à mulher idosa, essas normas estão longe de serem efetivadas. As Instituições no Sistema de Justiça continuam a se debruçar sobre o inócuo debate da competência para o processamento e julgamento dos crimes atinentes à violência doméstica contra a mulher idosa, em uma dualidade Vara da Mulher vs. Vara do Idoso, o qual também pode se vislumbrar o embate pela aplicação da Lei Maria da Penha vs. Estatuto do Idoso. Os tribunais tendem para o entendimento da competência da Vara da Mulher e, consequente aplicação da Lei Maria da Penha para a solução da controvérsia, posto ser, conforme disciplina Araújo (2018, p. 231-232), uma lei posterior ao Estatuto do Idoso e mais específica.

Aparentemente, esse conflito leva a afirmar que o aplicador do Direito deve se ater a uma das normas em detrimento da outra, isto é, à Lei Maria da Penha em detrimento do que dispõe o Estatuto do Idoso. Contudo, deve-se aqui expor a exclusão do debate e a falta de aplicação dos mecanismos internacionais de direito humanos da mulher idosa, como a Convenção de Belém do Pará e a Convenção Interamericana sobre a Proteção dos Direitos Humanos dos Idosos, haja vista que a dupla vulnerabilidade em que se encontra gera a necessidade de uma maior proteção. Restando-se evidente um grande prejuízo quanto à efetivação dos direitos humanos das mulheres na terceira idade.

A tese do diálogo das fontes emerge como uma solução adequada ao suposto conflito entre a Lei Maria da Penha e o Estatuto do Idoso. O magistrado, no seu papel de intérprete do Direito e criador da norma a ser aplicada ao caso concreto, deve promover um verdadeiro diálogo entre as fontes do Direito, a fim de que construa uma norma justa, completa e coerente. Acerca do papel interpretativo do julgador, Miguel Reale (2009, p. 95) observa 
$\mathrm{O}$ ato de julgar não obedece a meras exigências lógico-formais, implicando sempre apreciações valorativas (axiológicas) dos fatos, e, não raro, um processo de interpretação da lei, aplicável ao caso, graças a um trabalho que é antes de "dedução amplificadora". Muitas vezes, para julgar uma ação, o juiz é levado por força geral e unitária do ordenamento jurídico, a combinar preceitos, chegando a consequências normativas que não se continham, à primeira vista, nas proposições por ele criadoramente aproximadas.

Com isso, ao se abordar a violência doméstica contra a mulher idosa, não há o que se falar em utilização da Lei Maria da Penha, em detrimento das demais normativas nacionais ou internacionais. Muito ao contrário, por meio da tese do diálogo das fontes, há de se defender uma relação de reciprocidade e complementaridade entre a Lei Maria da Penha, Convenção de Belém do Pará, Estatuto do Idoso e as demais normas, as quais, somadas, possibilitam a maior proteção e garantia dos direitos humanos das mulheres idosas. Nessa linha, é inócuo o debate sobre a competência para o processamento e julgamento da violência doméstica contra a mulher idosa, posto que o relevante é a aplicação dos mecanismos de proteção a esse grupo vulnerável, à luz da tese do diálogo das fontes, independente da Vara em que venha a tramitar o processo.

O Estudo de caso de duas decisões da $2^{a}$ Vara da Comarca de Rosário no Estado do Maranhão

Inicialmente, insta salientar que a $2^{\mathrm{a}}$ Vara da Comarca de Rosário no Estado do Maranhão possui competência geral, posto ser de uma comarca de entrância inicial, conforme o art. $7^{\circ}$, inciso VIII do Código de Divisão e Organização Judiciárias do Estado do Maranhão. Dessa maneira, possui competência para demandas de matéria criminal e cível. 
A razão de tais decisões serem analisadas é de que, embora tratem de matérias distintas: uma concedendo medida protetiva de urgência (MPU) (MARANHÃO, 2019a) e outra acerca do direito real de habitação em processo de inventário, observa-se que, para além de um diálogo entre a Lei Maria da Penha (LMP) e o Estatuto do idoso (MARANHÃO, 2019b), na primeira, houve uma relação de nexo e influência da primeira decisão em relação à segunda, que merece atenção.

Na decisão atinente à concessão de MPU, tratava-se de representação formulada pela Senhora idosa $X$ em face de seus filhos $A$, B e C através da Delegacia Especial da Mulher de Rosário em razão de maus-tratos, ameaças e injúrias. No que concerne o Estatuto do Idoso e a LMP, o magistrado José Augusto Sá Costa Leite assim se pronunciou

[...] De início, cumpre observar que a Lei $\mathrm{n}^{\circ}$ $10.741 / 2003$, mais conhecida como o Estatuto do Idoso, em seus artigos 43 a 45, em um rol exemplificativo, dispõe sobre as medidas de proteção ao idoso, aplicáveis em casos de violação aos direitos reconhecidos neste mesmo diploma legal.

Por sua vez, a Lei $\mathrm{n}^{0} 11.340 / 2006$ trouxe em seu escopo a desconstrução do padrão cultural que autoriza a violência contra a mulher.

$[\ldots]$

Destarte, com fulcro na inteligência do artigo 22 da Lei $\mathrm{n}^{\circ} 11.340 / 2006$, DECRETO AS SEGUINTES MEDIDAS PROTETIVAS:

a) AFASTAMENTO dos representados do lar da ofendida, até ulterior determinação deste Juízo, ficando autorizada, desde já, a requisição de auxílio policial, em caso de necessidade para cumprimento da medida;

b) PROIBIÇÃO dos representados de se aproximarem da ofendida, e para tanto determino que mantenham uma distância mínima de 300 (trezentos) metros; 
c) PROIBICCÃO dos representados de deslocarem-se até a residência da vítima;

d) PROIBIČ̃̃O dos representados de fazerem contato com a ofendida, quer por telefone, meios eletrônicos (e-mails, whatsapp, facebook, etc.), bilhetes, recados, cartas, pessoalmente ou por meio de terceiros. (MARANHÃO, 2019a, p. 01-02).

Observa-se que, para a aplicação das citadas medidas protetivas de urgência, o magistrado não afastou de pronto as medidas protetivas previstas no Estatuto do Idoso. Nota-se que esse apenas asseverou o rol exemplificativo previsto nesse último diploma, de tal maneira que não atuou no sentido de excluir a aplicação do Estatuto do Idoso ao caso em tela, mas acentuou a complementaridade que o próprio diploma do idoso permitiu e, em razão do gênero da vítima, aplicou as hipóteses previstas na LMP, por ser norma que possibilita a melhor forma de atingir a finalidade dos dois diplomas legais em tela frente ao citado caso concreto, assegurando os direitos humanos da mulher idosa. Sendo, assim, verifica-se um verdadeiro exemplo de diálogo entre as fontes.

Contudo, o diálogo em estudo não se encerrou apenas com a decisão de concessão de MPU. Em outro processo, este em matéria cível, no âmbito de ação de inventário em que o de cujus era marido da Senhora idosa $X$, essa última solicitou o direito real de habitação no único bem deixado pelo falecido, isto é, a casa em que morava. O juízo da $2^{\text {a }}$ Vara da Comarca de Rosário/MA assim decidiu

In casu, verifica-se que a herança é composta basicamente pelo bem imóvel em testilha, razão pela qual não há motivos idôneos para se impedir a requerente de usufruir da moradia no imóvel.

Há que se considerar ainda que este Juízo já deferiu em favor da demandante Medida Protetiva de Urgência, que acaso desobedecida, poderá ensejar a responsabilização criminal dos envolvidos. (MARANHÃO, 2019b, p. 04). 
Nesse sentido, houve um diálogo entre a LMP e o próprio Código Civil (CC) em uma relação de influência e complementaridade. Embora a Senhora idosa $\mathrm{X}$ tenha seu direito real de habitação assegurado nos moldes do art. 1.831 do $\mathrm{CC}^{16}$, o fato de a ela terem sido dirigidas MPUs, com o afastamento dos demais herdeiros do seu local de residência, dá maior fundamento e necessidade de garantia do seu direito, tanto de moradia, quanto integridade física e moral.

Dessa maneira, a partir das citadas decisões da $2^{\mathrm{a}}$ Vara da Comarca de Rosário/MA, restou-se claramente demonstrado como a tese do diálogo das fontes é um instrumento de interpretação salutar, na medida em que não exclui nenhuma norma protetiva, subsidiando a garantia dos direitos humanos das mulheres idosas em situações de violência doméstica e ou familiar.

\section{Considerações finais}

A população brasileira, desde a década de 70 , passa por um processo gradual de envelhecimento. Evidenciou-se que, atrelado ao citado processo, está o fenômeno da feminização da velhice a qual, mais do que uma simples questão demográfica em que o número de idosas supera o de idosos, caracteriza-se pela discussão tanto no âmbito público, quanto privado de questões como o gênero e patriarcado, políticas públicas, garantias de direitos e atuação estatal acerca desse grupo vulnerável.

Ademais, demonstrou-se o grave quadro de violência doméstica contra a mulher idosa no país, como resultado de uma omissão estatal e despreparo das suas autoridades públicas e suas instituições frente a esse tipo de violência. Vale ressaltar que, além da omissão do Estado, o fato de ser uma violência silenciosa, atinente ao ambiente doméstico,

16 "Art. 1.831. Ao cônjuge sobrevivente, qualquer que seja o regime de bens, será assegurado, sem prejuízo da participação que lhe caiba na herança, o direito real de habitação relativamente ao imóvel destinado à residência da família, desde que seja o único daquela natureza a inventariar." 
somada a proximidade afetiva das vítimas com seus agressores, em grande parte, filhos e netos, diminuem os números de denúncias e agravam todo o cenário.

Denotou-se que, embora haja um arcabouço jurídico nacional e internacional de proteção à mulher idosa, essas normas estão longe de serem efetivadas. As Instituições do Sistema de Justiça continuam a se debruçar sobre o inócuo debate da competência para o processamento e julgamento dos crimes atinentes à violência doméstica contra a mulher idosa, em uma dualidade Vara da Mulher vs. Vara do Idoso o qual também pode se vislumbrar o embate pela aplicação da Lei Maria da Penha vs. Estatuto do Idoso. Prevalecendo o posicionamento pela competência da Vara da Mulher, consequentemente, levantando a errônea impressão da aplicação da LMP e exclusão do Estatuto do Idoso.

Além disso, constatou-se que a tese do diálogo das fontes surgiu como uma necessidade de solução de conflitos de normas frente à complexidade das novas problemáticas sociais e das normas integrantes dos ordenamentos jurídicos, posto que os critérios de solução tradicionais (hierárquico, cronológico e de especialidade) não são suficientes. Diferente desses últimos, a tese do diálogo das fontes possibilita a coexistência e harmonia entre as duas normas inicialmente conflitantes, inclusive quando se tratam de normas de direito internacional e de direito interno, devendo o magistrado assegurar uma aplicação justa e equilibrada dos dispositivos, sem a exclusão ou invalidação de quaisquer das normas em conflito.

Nesse ínterim e analisando as decisões objeto do presente estudo de caso, verificou-se que por meio da tese do diálogo das fontes, há de se defender uma relação de reciprocidade e complementariedade entre a Lei Maria da Penha, Convenção de Belém do Pará, Estatuto do Idoso e as demais normas, as quais, somadas possibilitam a maior proteção e garantia dos direitos humanos das mulheres idosas. Nessa linha, é inócuo o debate sobre a competência para o processamento e julgamento da violência doméstica contra a mulher idosa, posto que o 
relevante é a aplicação dos mecanismos de proteção a esse grupo vulnerável à luz da tese dos diálogos das fontes, independentemente da Vara em que venha a tramitar o processo.

\section{Referências}

ARAÚJO, Yélena de Fátima Monteiro. Violência doméstica + idosa = Lei Maria da Penha, será? In: BRASIL. Conselho Nacional do Ministério Público. Violência contra a mulher: um olhar do Ministério Público brasileiro/Conselho Nacional do Ministério Público. Brasília: CNMP, 2018. p. 220-235.

$\begin{array}{ccccccc}\text { AUMENTAM } & \text { AS } & \text { DENÚNCIAS } & \text { DE } & \text { VIOLÊNCIA CONTRA } & \text { OS } \\ \text { IDOSOS. } & \text { G1. } & 15 & \text { jun. } & 2019 . & \text { Disponível } & \text { em: }\end{array}$ <https://g1.globo.com/jornalnacional/noticia/2019/06/15/aumentam-as-denuncias-deviolencia-contra-os-idosos.ghtml>. Acesso em 02 abril 2019.

BILYNSKYJI, Daniela Atab Del Nero. Direito do Idoso. In: KIAN, Fátima Aparecida; ANDRADE, Vander Ferreira De (Coord.). Direito das minorias e grupos vulneráveis. 1. ed. São Paulo: Editora Nepal, 2016. p. 55-73.

BRASIL. Código de Divisão e Organização Judiciária no Estado do Maranhão. Disponível em: <https://www.migalhas.com.br/arquivo_artigo/art2013040913.pdf>. Acesso em: 05 jul. 2019.

BRASIL. Constituição da República Federativa do Brasil de 1988. Brasília, DF: $1988 . \quad$ Disponível em: <http://www.planalto.gov.br/ccivil_03/constituicao/constituicao.h tm>. Acesso em: 05 jun. 2019.

BRASIL. Decreto-Lei $n^{\circ} 4657 / 42$. Lei de Introdução às normas do Direito Brasileiro. Brasília, DF: 2010. Disponível em: < http:// www.planalto.gov.br/ccivil_03/Decreto-Lei/Del4657.htm>. Acesso em: 05 jun. 2019.

BRASIL. Lei 10.741, de 01 de outubro de 2003. Dispõe sobre o Estatuto do Idoso e dá outras providências. Brasília, DF: 2003. Disponível em: <http:/ / www.planalto.gov.br/ccivil_03/leis/2003/110.741.htm\#: :t 
ext=LEI $\% 20$ No $\% 2010.741 \% 2$ C $\% 20$ DE $\% 201 \%$ C2\%BA $\% 20$ DE $\% 20$ OUT UBRO \%20DE\%202003.\&text=Disp\%C3\%B5e\%20sobre\%20o\%20Estat uto $\% 20$ do $\% 20$ Idoso $\% 20 \mathrm{e} \% 20 \mathrm{~d} \%$ C3\%A1\%20outras\%20provid \% C3\% AAncias.\&text $=$ Art.,a\%2060\%20(sessenta) $\% 20$ anos. $>$. Acesso em: 08 jun. 2019.

BRASIL. Lei 8.842, de 04 de janeiro de 1994. Dispõe sobre a Política Nacional do Idoso, cria o Conselho Nacional do Idoso e dá outras providências. Brasília, DF: 1994. Disponível em: <http:/ / www.planalto.gov.br/ccivil_03/leis/L8842.htm\#: :text=LE I\%20N\% C2\%BA \% 208.842\%2C\%20DE\% 204\%20DE\%20JANEIRO $\% 20$ DE\%201994.\&text=Disp\%C3\%B5e\%20sobre\%20a\%20pol\%C3\%ADtic a\%20nacional,Idoso\%20e\%20d\%C3\%A1\%20outras\%20provid\%C3\% AAncias.. >. Acesso em: 06 jun. 2019.

CONVENÇÃO INTERAMERICANA PARA PREVENIR, PUNIR E ERRADICAR A VIOLÊNCIA CONTRA A MULHER, "CONVENÇÃO DE BELÉM DO PARÁ". 1994. Disponível em: <http://www.cidh.org/Basicos/Portugues/m.Belem.do.Para.htm>. Acesso em: 08 jul. 2019.

CONVENÇÃO INTERAMERICANA SOBRE A PROTEÇÃO DOS DIREITOS HUMANOS DOS IDOSOS. 16 jun. 2015. Disponível em: <http:/ / www.ampid.org.br/v1/wpcontent/uploads/2014/08/conven $\%$ C3\% A7\%C3\%A3ointeramericana-sobre-a-prote $\% \mathrm{C} 3 \% \mathrm{~A} 7 \% \mathrm{C} 3 \% \mathrm{~A} 3 \mathrm{o}$-dos-direitoshumanos-dos-idosos-OEA.pdf>. Acesso em: 01 jun. 2019.

DELPHY, Christine. Patriarcado (teorias do). In: HIRATA, Helena et al. (Org.). Dicionário Crítico do Feminismo. São Paulo: Editora UNESP, 2009. p 173-178.

EGYDIO, Lucila. Do feminismo à feminização: Gênero e Envelhecimento em uma sociedade em transformação. Revista Portal de Divulgação, n. 54, ano VIII, out./nov./dez. 2017. Disponível em: $<$ https://revistalongeviver.com.br/index.php/revistaportal/article /view/686/756>. Acesso em 02 jul. 2019.

FUNDO DE POPULAÇÃO DA ONU ALERTA PARA A VIOLÊNCIA CONTRA OS IDOSOS NO BRASIL. ONU Brasil. 19 jun. 2018. Disponível em: <https:/ / nacoesunidas.org/fundo-de-populacao-da- 
onu-alerta-para-violencia-contra-idosos-no-brasil/>. Acesso em 02 jul. 2019.

IBGE - INSTITUTO BRASILEIRO DE GEOGRAFIA E ESTATÍSTICA, 2018. Projeção da População do Brasil e Unidades da Federação por sexo e idade para o período 2010-2060. Rio de Janeiro: IBGE.

KELSEN, Hans. Teoria Pura do Direito. 7. ed. São Paulo: Martins Fontes, 2006.

MARANHÃO. Tribunal de Justiça do Maranhão. Decisão do Processo $\mathrm{n}^{\circ}$ 0800868-71.2019.8.10.0115. Juiz de Direito da $2^{\mathrm{a}}$ Vara da Comarca de Rosário/MA José Augusto Sá Costa Leite. Diário de Justiça do Estado do Maranhão. 14 maio 2019a.

MARANHÃO. Tribunal de Justiça do Maranhão. Decisão do Processo $\mathrm{n}^{\circ}$ 0800917-15.2019.8.10.0115. Juiz de Direito da $2^{\mathrm{a}}$ Vara da Comarca de Rosário/MA José Augusto Sá Costa Leite. Diário de Justiça do Estado do Maranhão. 13 maio 2019b.

MARQUES, Cláudia Lima. Diálogo das fontes. In: BENJAMIN, Antonio Herman V.; MARQUES, Claudia Lima; BESSA, Leonardo Roscoe. Manual de direito do consumidor. 5. ed. rev., atual. e ampl. São Paulo: Revista dos Tribunais, 2013, p. 128.

MAZZUOLI, Valerio de Oliveira. Rumo às novas relações entre o direito internacional dos direitos humanos e o direito interno: da exclusão à coexistência, da intransigência ao diálogo das fontes. 2008. Tese (Doutorado em Direito) - Universidade Federal do Rio Grande do Sul/Faculdade de Direito, Porto Alegre, 2008. Disponível em: <https://lume.ufrgs.br/bitstream/handle/10183/132783/000680945 .pdf?sequence=1\&isAllowed=y>. Acesso em: 04 jul. 2019.

MIRANDA, Gabriella Moraes Duarte; MENDES, Antonio da Cruz Gouveia, SILVA, Ana Lucia Andrade da. O envelhecimento populacional brasileiro: desafios e consequências atuais e futuras. Revista brasileira de Geriatria e Gerontologia, v. 9, n. 3, 2016. Disponível em: <http://www.scielo.br/pdf/rbgg/v19n3/pt_1809-9823-rbgg19-03-00507.pdf>. Acesso em 18 jun. 2019.

NICODEMO, Denise; GODOI, Marilda Piedade. Juventude dos anos 6070 e envelhecimento: estudo de casos sobre feminização e direitos de mulheres idosas. Revista Ciência em Extensão, v. 6, n. 1, 2010. Disponível 
em:

http://ojs.unesp.br/index.php/revista_proex/article/view/324/34 1. Acesso em: 27 jun. 2019.

PARADELLA, Rodrigo. Número de idosos cresce 18\% em 5 anos e ultrapassa 30 milhões em 2017. Agência IBGE notícias. 26 abr. 2018. Disponível em: <https://agenciadenoticias.ibge.gov.br/agencianoticias/2012-agencia-de-noticias/noticias/20980-numero-deidosos-cresce-18-em-5-anos-e-ultrapassa-30-milhoes-em-2017.html>. Acesso em 17 ago. 2018.

REALE, Miguel. Lições pre-liminares de Direito. 25 ed. São Paulo: Saraiva, 2009.

SAFFIOTI, Heleieth Iara Bongiovani. Gênero, Patriarcado e violência. São Paulo: Fundação Perseu Abramo, 2004.

SALGADO, C. D. S. Mulher idosa: a feminização da velhice. Estudos Interdisciplinares sobre o Envelhecimento, v. 4, p. 7-19, 2002. Disponível em:

<http:/ / seer.ufrgs.br/index.php/RevEnvelhecer/article/view/4716 /2642>. Acesso em: 26 jun. 2019.

TARTUCE, Flávio. Manual de Direito Civil: volume único. 8. ed. Rio de Janeiro: Forense; São Paulo: Método, 2018.

VELOSO, Aparecida Fernanda Albuquerque Pinto. A atuação do Poder Judiciário maranhense na apreciação dos casos de violência doméstica e intrafamiliar contra a mulher idosa na comarca de São Luís do Maranhão. 2016. Dissertação (Mestrado em Direito) - Universidade Federal do Maranhão, São Luís, 2016. 